\title{
PENGARUH APLIKASI TRIPLE SUPER PHOSPHATE (TSP) DALAM MENINGKATKAN PRODUKSI TANAMAN KACANG PANJANG (Vigna sinensis L.)
}

\author{
Nursayuti ${ }^{1}$ \\ Dosen Fakultas Pertanian Program studi Agroteknologi Universitas Almuslim Matang \\ glumpang Dua Bireuen \\ Email: nursayuti1979@gmail.com
}

\begin{abstract}
ABSTRAK
Penelitian ini bertujuan untuk mengetahui pengaruh aplikasi pupuk Triple Super Phosphate (TSP) dalam meningkatkan hasil tanaman kacang panjang. Penelitian ini dilaksanakan di Gampong Alue Kupula Kecamatan Peusangan Siblah Krueng Kabupaten Bireuen dengan ketinggian tempat $560 \mathrm{mdpl}$ yang dimulai pada tanggal 03 Juli sampai dengan tanggal 25 September 2019. Rancangan percobaan yang dilakukan dalam penelitian ini adalah Rancangan Acak Kelompok (RAK) non faktorial dengan perlakuan. sebagai berikut : Pupuk TSP (T) terdiri dari 3 taraf perlakuan yaitu : $\mathrm{T}_{0}=0 \mathrm{~g} /$ tanaman (kontrol), $\mathrm{T}_{1}=0,6 \mathrm{~g} /$ tanaman, dan $\mathrm{T}_{2}=1,20 \mathrm{~g} /$ tanaman. Pengamatan yang diamati dalam penelitian ini meliputi tinggi tanaman, jumlah polong, jumlah polong pertandan, panjang polong, berat polong, berat 100 biji dan produktivitas (ton/ha). Hasil penelitian menunjukkan pemberian pupuk TSP berpengaruh sangat nyata terhadap pertumbuhan tinggi tanaman umur 20, 40 dan 60 HST, jumlah polong, jumlah polong per tandan, panjang polong dan berat 100 biji tanaman kacang panjang. Perlakuan terbaik dijumpai pada perlakuan pupuk TSP dengan dosis 1,20 g/tanaman $\left(\mathrm{T}_{2}\right)$.
\end{abstract}

Kata Kunci : Aplikasi,kacang panjang, pupuk TSP 


\section{PENDAHULUAN}

Kacang panjang merupakan tanaman sayuran yang populer dalam kuliner Asia Tenggara dan Asia Timur. Produksi kacang panjang yang dihasilkan di Indonesiayaitu sebesar 6,26 ton /ha, namun demikian tanaman kacang panjang ini termasuk jenis sayuran yang persentase produksinya kurang dari tujuh persen, pada tahun 2015 produksi kacang panjang di Kabupaten Bireuen mencapai 31.572 ton/Ha dengan luas tanam 264 Ha kemudian produksi menurun pada tahun 2017 menjadi 3.342 ton/Ha dengan luas tanam 239 Ha (BPS, 2017), hal ini menunjukkan produksi tanaman kacang panjang di di Bireuen mengalami penurunan secara drastis dari tahun ketahun. Penurunan produktivitas kacang panjang di Kabupaten Bireuen disebabkan oleh belum maksimalnya pengetahuan petani dalam penggunaan teknologi produksi yang mendukung pertanian berkelanjutan dan semakin berkurangnya sumber daya lahan yang subur (Jumrawati, 2017).

Adapun upaya yang dapat dilakukan untuk memenuhi akan tersedianya unsur hara dan produksi tanaman kacang panjang dapat ditempuh dengan pemberian pupuk TSP. Pupuk TSP (Triple Super Phosphate) adalah pupuk anorganik yang mengandung P dan Ca dengan kadar $\mathrm{P}_{2} \mathrm{O}_{5}$ mencapai $44-46 \%$ dan $\mathrm{CaO}$ mencapai 20\%. Fosfat sangat diperlukan oleh tanaman pada saat pembentukan biji sehingga menjadi bentuk yang sempurna dan untuk mempercepat kemasakan buah serta tahan terhadap kekeringan. Kekurangan P pada kebanyakan tanaman terjadi sewaktu tanaman masih muda, karena belum adanya kemampuan yang seimbang antara penyerapan $\mathrm{P}$ oleh akar dan $\mathrm{P}$ yang dibutuhkan (Barus et $a l$, 2014). Menurut penelitian pemberian TSP untuk kacang hijau telah berhasil meningkatkan hasil kering panen, jumlah polong per tanaman, biji per polong, bobot 1000 butir, hasil biji dan biomassa total.

Hasil penelitian Rosmawaty dkk. (2017) menunjukkan bahwa pemberian MOL Keong Mas dan pupuk TSP berpengaruh nyata terhadap jumlah polong bernas per tanaman, berat polong kering per tanaman dan berat kering biji per tanaman. Perlakuan terbaik adalah MOL keong mas $45 \mathrm{ml} / 2 \mathrm{~L}$ air dan pupuk TSP 1,20 g/tanaman kacang tanah.

\section{BAHAN DAN METODE PENELITIAN}


Penelitian ini dilaksanakan di Gampong Alue Kupula Kecamatan Peusangan Siblah Krueng Kabupaten Bireuen dengan ketinggian tempat 560 mdpl yang dimulai pada tanggal 03 Juli sampai dengan tanggal 25 September 2019.

Alat yang digunakan cangkul, drum, ember, kayu pengaduk, batu, blender, saringan, gelas ukur, gembor, meteran, gunting, papan nama, kamera, alat tulis, dan timbangan digital. Bahan yang digunakan benih kacang panjang Varietas Peleton, ajir, tali raffia, pupuk TSP, Rancangan yang digunakan dalam penelitian ini adalah Rancangan Acak Kelompok (RAK) faktorial yang terdiri dari: Pupuk TSP $(\mathrm{T})$ terdiri dari 3 taraf : $\mathrm{T}_{0}=0 \mathrm{~kg} / \mathrm{Ha}$ (kontrol), $\mathrm{T}_{1}=50$ $\mathrm{kg} / \mathrm{Ha}(7,2 \mathrm{~g} / \mathrm{plot}), \mathrm{T}_{2}=100 \mathrm{~kg} / \mathrm{Ha}(14,4 \mathrm{~g} / \mathrm{plot})$. Model matematika yang digunakan untuk Rancangan Acak Kelompok (RAK) Non Faktorial (Tapehe, Yusuf. 2015.)

$$
Y \mathbf{i j}=\boldsymbol{\mu}+\boldsymbol{\beta} \mathbf{i}+\boldsymbol{\tau} \mathbf{j}+\varepsilon \mathbf{i j k} \text {. }
$$

Adapun parameter yang diamati adalah sebagai berikut: tinggi tanaman $(\mathrm{cm})$, jumlah polong Pertanaman (polong), jumlah polong pertandan, panjang polong $(\mathrm{cm})$, berat polong pertanam berat $100 \mathrm{Biji}(\mathrm{g})$, dan produktivitas (Ton/Ha)

\section{Tahapan Penelitian}

\section{Persiapan Lahan dan Pengolahan Tanah}

Persiapan areal lahan diawali dengan melakukan pembersihan lahan dari gulma dengan cara dicabut. Pengolahan tanah dilakukan dengan menggunakan cangkul. Pencangkulan lahan dilakukan dengan memindahkan tanah bagian bawah sedalam $30 \mathrm{~cm}$ keatas permukaan lahan. Selanjutnya dilakukan pengemburan tanah kembali dengan cara membalikkan tanah untuk menyeimbangkan ketersediaan unsur hara antara bagian bawah dan atas lahan.

\section{Pembuatan Plot}

Plot percobaan dibuat sebanyak 36 plot, dengan ukuran plot percobaan 1.50 meter x 1 meter, dengan jarak antar plot $50 \mathrm{~cm}$ dan antar ulangan $50 \mathrm{~cm}$. Setelah pembuatan plot dilakukan pemberian pupuk dasar yaitu pupuk kandang sapi dengan perbandingan 10 ton/ha. Setelah dilakukan pemupukan, di biarkan selama 7 hari agar pupuk kandang dapat tercampur dan terurai dengan sempurna didalam tanah.

\section{Aplikasi Pupuk TSP}

Pemberian pupuk dilakukan sebanyak 1 kali yaitu pada saat tanam dengan dosis sesuai perlakuan masing-masing. Cara pemberian pupuk TSP yaitu dengan cara membuat 
lubang tanam dengan jarak $2 \mathrm{~cm}$ dari lubang tanam tanaman dan pupuk ditaburkan pada lubang kemudian di tutup dengan tanah.

\section{Penanaman Kacang Panjang}

Penanaman benih kacang panjang dilakukan dengan cara membuat lubang dengan mengunakan tugal pada plot percobaan dengan jarak tanam $50 \mathrm{~cm}$ x $20 \mathrm{~cm}$. Setiap lubang diisi dengan 2 biji kacang panjang. Kemudian menutupi lubang dengan tanah tipis sehingga tunas bisa keluar dengan mudah. Setelah penanaman benih selesai, dilakukan penyiraman pertama dengan menggunakan gembor secara merata.

\section{Pemeliharaan}

\section{Penyiraman}

Penyiraman tanaman kacang panjang dilakukan 2 kali sehari pada pagi dan sore hari. Penyiraman dilakukan dengan menggunakan alat penyiram yaitu gayung dengan volume air disesuikan dengan kondisi lingkungan. Apabila terjadi hujan maka penyiraman tidak perlu dilakukan.

\section{Pembuatan ajir}

Ajir untuk membantu pertumbuhan tanaman kacang panjang agar tumbuh dengan baik dan tidak menumpuk tak menentu, maka dibuatkan ajir. Ajir dibuat dari bambu dengan panjang $2 \mathrm{~m}$. Pemasangan ajir dilakukan saat tinggi tanaman kacang panjang sudah mencapai $25 \mathrm{~cm}$.

\section{Penyiangan}

Penyiangan pada tanaman kacang panjang dilakukan dengan membersihkan gulma yang tumbuh di sekitar tanaman yang dilakukan pada saat tanaman berumur 20 HST dan 40 HST

\section{Pengendalian hama penyakit}

Untuk mengendalikan hama penyakit, pengendalian yang dilakukan dengan cara manual dengan cara memotong atau memindahkan hama pada daun tanaman yang terserang.

\section{Pemanenan}

Tanaman kacang panjang dapat mulai dipanen setelah berumur 45 hari setelah tanam dengan ciri-ciri kacang panjang yang siap dipanen polongnya sudah terisi penuh, polongnya 
mudah dipatahkan dan warna polong kacang panjang merata sampai hijau keputihan. Panen kacang panjang dilakukan dengan cara dipetik yaitu dengan cara memutar bagian pangkal polong hingga polong terlepas. Waktu panen kacang panjang dilakukan pada pagi hari karena pada pagi hari polong kacang masih segar. Pemanenan kacang panjang dilakukan setelah berselang waktu sekitar 5 hari.

\section{HASIL DAN PEMBAHASAN}

\section{Pengaruh Pupuk TSP}

\section{Tinggi Tanaman $(\mathrm{cm})$}

Nilai rata-rata tinggi tanaman kacang panjang pada umur 20, 40 dan 60 HST akibat perlakuan pupuk TSP setelah diuji BNT 0,05 di sajikan pada Tabel 1.

Tabel 1. Nilai Rata-rata Tinggi Tanaman Kacang Panjang Pada Umur 20, 40 dan 60 HST Akibat Perlakuan Pupuk TSP

\begin{tabular}{llll}
\hline \multirow{2}{*}{ Pupuk TSP } & \multicolumn{2}{l}{ Tinggi Tanaman $(\mathrm{cm})$} \\
\cline { 2 - 4 } & $20 \mathrm{HST}$ & $40 \mathrm{HST}$ & $60 \mathrm{HST}$ \\
\hline $\mathrm{T}_{0}$ & $76.05^{\mathrm{a}}$ & $126.20^{\mathrm{a}}$ & $142.33^{\mathrm{a}}$ \\
$\mathrm{T}_{1}$ & $84.10^{\mathrm{b}}$ & $129.35^{\mathrm{b}}$ & $144.74^{\mathrm{b}}$ \\
$\mathrm{T}_{2}$ & $81.81^{\mathrm{a}}$ & $130.05^{\mathrm{b}}$ & $146.45^{\mathrm{b}}$ \\
\hline $\mathrm{BNT}_{0,05}$ & 5.94 & 1.77 & 1.75
\end{tabular}

Keterangan :Angka yang diikuti oleh huruf yang sama pada kolom yang sama berbeda tidak nyata pada Uji BNT 0.05

Tabel 1 memperlihatkan bahwa perlakuan pupuk TSP berpengaruh sangat nyata terhadap pertumbuhan tinggi tanaman kacang panjang pada umur 20, 40 dan 60 HST. Tinggi tanaman tanaman kacang panjang tertinggi pada umur 20 HST dijumpai pada perlakuan pupuk TSP dosis $0,6 \mathrm{~g} / \operatorname{tanaman}\left(\mathrm{T}_{1}\right)$ dan pada umur 40 dan 60 HST dijumpai pada perlakuan pupuk TSP dosis 1,20 g/tanaman $\left(\mathrm{T}_{2}\right)$ sedangkan perlakuan terendah pada umur 20, 40 dan 60 HST dijumpai pada perlakuan kontrol $\left(\mathrm{T}_{0}\right)$. Hal ini disebabkan bahwa unsur hara yang dibutuhkan tanaman kacang panjang pada pertumbuhan tinggi tanaman pada umur 20 HST sudah tercukupi, karena pada saat tanaman memasuki tahap awal pertumbuhan tanaman masih memanfaatkan cadangan makanan yang terdapat dalam benih. 
Umur 40 dan 60 HST tanaman kacang panjang memelukan unsur TSP dalam dosis tinggi dalam memicu pertumbuhan tinggi tanaman selanjutnya. Hal ini menunjukkan bahwa semakin meningkatnya dosis pupuk TSP yang diberikan maka akan semakin meningkatkan pula pertumbuhan tinggi tanaman kacang panjang. Hal ini disebabkan oleh pemberian pupuk TSP mampu menghidrolisis fosfolipida dengan adanya enzim fosfat yang dapat mengubah senyawa fosfor menjadi tersedia bagi tanaman sehingga terbukti mampu memberikan pengaruh yang baik bagi pertumbuhan tanaman kacang panjang.

Sesuai dengan pendapat Sarief (2016) yang menyatakan bahwa fosfor berperan dalam menyusun tubuh tanaman dan beberapa koenzim yang berperan dalam aktivitas metabolisme. Dengan meningkatnya aktivitas metabolisme, bahan organik yang terbentuk cukup tersedia sehingga akan dihasilkan karbohidrat dan diubah menjadi organ-organ tanaman seperti batang. Novizan (2012), menyatakan bahwa fosfat merupakan bagian dari protoplasma dan inti sel yang sangat penting dalam pembentukkan sel dan perkembangan jaringan meristem ujung, sehingga pemberian pupuk TSP dapat menyediakan unsur fosfat sehingga dapat meningkatkan pertumbuhan tinggi tanaman.

Unsur P merupakan bagian penting dalam metabolisme tanaman sebagai pembentuk gula fosfat yang dibutuhkan tanaman pada saat fotosintesis. Fotosintesis yang berjalan dengan baik akan menghasilkan fotosintat yang dapat digunakan tanaman untuk pertumbuhan dan perkembangan tanaman. Lakitan (2004) menyatakan bahwa akar, batang dan daun merupakan bagian tanaman yang memanfaatkan fotosintat selama fase vegetatif. 


\section{Jumlah Polong Per Tanaman (polong)}

Nilai rata-rata jumlah polong per tanaman kacang panjang panen I, II, III, IV dan V akibat perlakuan pupuk TSP setelah diuji BNT 0,05 di sajikan pada Tabel 2.

Tabel 2. Nilai Rata-rata Jumlah Polong Per Tanaman Kacang Panjang Pada Panen I, II, III, IV dan V Akibat Perlakuan Pupuk TSP

\begin{tabular}{cccccc}
\hline \multirow{2}{*}{ Pupuk TSP } & \multicolumn{5}{c}{ Jumlah Polong per Tanaman (polong) } \\
\cline { 2 - 6 } & I & II & III & IV & V \\
\hline $\mathrm{T}_{0}$ & $8.12^{\mathrm{a}}$ & $8.76^{\mathrm{a}}$ & $10.55^{\mathrm{a}}$ & $8.55^{\mathrm{a}}$ & 7.99 \\
$\mathrm{~T}_{1}$ & $8.93^{\mathrm{a}}$ & $9.87^{\mathrm{a}}$ & $10.43^{\mathrm{a}}$ & $8.77^{\mathrm{a}}$ & 8.20 \\
$\mathrm{~T}_{2}$ & $9.26^{\mathrm{b}}$ & $9.95^{\mathrm{b}}$ & $11.20^{\mathrm{b}}$ & $9.20^{\mathrm{b}}$ & 8.28 \\
\hline $\mathrm{BNT}_{0,05}$ & 0.85 & 0.43 & 0.54 & 0.41 & -
\end{tabular}

Keterangan : Angka yang diikuti oleh huruf yang sama pada kolom yang sama berbeda tidak nyata pada Uji BNT 0.05

Tabel 2 memperlihatkan bahwa perlakuan pupuk TSP berpengaruh sangat nyata terhadap jumlah polong per tanaman kacang panjang pada panen I, II, III dan IV dan berpengaruh tidak nyata terhadap jumlah polong tanaman kacang panjang pada panen $\mathrm{V}$. Jumlah polong per tanaman kacang panjang tertinggi pada panen I, II, III dan IV dijumpai pada perlakuan pupuk TSP dosis $1,20 \mathrm{~g} / \operatorname{tanaman}\left(\mathrm{T}_{2}\right)$. Adapun perlakuan terendah pada panen I, II, III dan IV dijumpai pada perlakuan kontrol $\left(\mathrm{T}_{0}\right)$. Hal ini disebabkan oleh pemberian pupuk TSP dengan dosis tersebut mampu menyediakan unsur hara $\mathrm{P}$ dengan optimal untuk diserap oleh tanaman kacang panjang dalam proses memicu pertumbuhan jumlah polong.

Terpenuhinya kebutuhan hara $\mathrm{P}$ maka akan meningkatkan aktivitas metabolisme sehingga bahan organik yang ditranslokasikan ke biji atau polong kacang juga meningkat. Unsur fosfor sangat diperlukan untuk pembentukan atau pertumbuhan generatif tanaman dengan adanya unsur fosfat yang cukup dalam tanah dapat memacu pembentukan polong pada tanaman kacang panjang. Ketersediaan unsur $\mathrm{P}$ penting untuk produksi kacang panjang, diantaranya dalam meningkatkan aktivitas metabolisme sehingga bahan organik yang ditranslokasikan ke polong kacang ikut meningkat dan ukuran polong yang lebih besar dan dapat berkontribusi pada hasil panen yang lebih tinggi (Hardjoloekito, 2012). Hidayat (2014), mengemukakan bahwa unsur fospor yang terdapat pada pupuk TSP berperan memperbaiki pertumbuhan generatif terutama pembentukan polong dan biji. Apabila 
pertumbuhan vegatatif baik, fotosintat yang dihasilkan semakin banyak, hal ini menyebabkan kemampuan tanaman untuk membentuk organ-organ generatif semakin meningkat.

Pertumbuhan jumlah polong per tanaman kacang panjang pada panen $\mathrm{V}$ berpengaruh tidak nyata. Hal ini disebabkan oleh ketersediaan unsur hara didalam tanah yang semakin berkurang, karena sudah dimanfaatkan pada panen I, II, III dan IV, selain itu juga disebabkan oleh umur tanaman yang semakin tua. Menurunnya jumlah polong pada panen $\mathrm{V}$ disebabkan oleh umur tanaman kacang panjang yang semakin tua, sehingga tanaman kacang panjang tidak mampu berproduksi jumlah polong dalam jumlah yang tinggi.

\section{Jumlah Polong Per Tandan (polong)}

Nilai rata-rata jumlah polong per tandan tanaman kacang panjang panen I, II, III, IV dan V akibat perlakuan pupuk TSP setelah diuji BNT 0,05 di sajikan pada Tabel 3.

Tabel 3. Nilai Rata-rata Jumlah Polong Per Tandan Tanaman Kacang Panjang Pada Panen I, II, III, IV dan V Akibat Perlakuan Pupuk TSP

\begin{tabular}{cccccc}
\hline \multirow{2}{*}{ Pupuk TSP } & \multicolumn{5}{c}{ Jumlah Polong per Tandan (polong) } \\
\cline { 2 - 6 } & I & II & III & IV & V \\
\hline $\mathrm{T}_{0}$ & 1.81 & $1.93^{\mathrm{a}}$ & 1.89 & 1.62 & $1.51^{\mathrm{a}}$ \\
$\mathrm{T}_{1}$ & 2.00 & $2.10^{\mathrm{b}}$ & 1.85 & 1.62 & $1.49^{\mathrm{a}}$ \\
$\mathrm{T}_{2}$ & 1.93 & $1.95^{\mathrm{a}}$ & 1.97 & 1.64 & $1.68^{\mathrm{b}}$ \\
\hline $\mathrm{BNT}_{0,05}$ & - & 0.11 & - & - & 0.13
\end{tabular}

Keterangan : Angka yang diikuti oleh huruf yang sama pada kolom yang sama berbeda tidak nyata pada Uji BNT 0.05

Tabel 3 memperlihatkan bahwa perlakuan pupuk TSP berpengaruh nyata terhadap jumlah polong per tandan tanaman kacang panjang pada panen II dan V dan berpengaruh tidak nyata terhadap jumlah polong per tandan pada panen I, III dan IV. Jumlah polong per tandan tanaman kacang panjang tertinggi pada panen II dijumpai pada perlakuan pupuk TSP dosis $0,6 \mathrm{~g} / \operatorname{tanaman}\left(\mathrm{T}_{1}\right)$ dan pada panen $\mathrm{V}$ dijumpai pada perlakuan pupuk TSP dosis 1,20 $\mathrm{g} /$ tanaman $\left(\mathrm{T}_{2}\right)$. Hal ini disebabkan bahwa pada pertumbuhan jumlah polong pertandan pada panen I, III dan IV unsur hara fosfat yan diberikan melalui pupuk TSP tidak berada dalam keadaan optimal untuk diserap tanaman kacang panjang dalam memicu pertumbuhan jumlah polong per tandan,

Produksi tanaman ditentukan oleh laju fotosintesis dan laju tersebut dikendalikan oleh ketersediaan unsur hara dan air pada tanah. Ketersediaan unsur hara dalam tanah sangat berperan penting dalam proses metabolisme tanaman, pada umumnya pertumbuhan dan hasil 
tanaman berkaitan erat dengan ketersedian unsur hara dan kondisi lingkungan yang optimal. apabila unsur hara tidak tersedia dalam jumlah yang tepat atau kelebihan maka unsur hara tersebut akan dapat mengurangi efesiensi dari hara yang lain (Novizan, 2012).

Jumlah polong per tandan tanaman kacang panjang pada panen II dan V berpengaruh nyata. Hal ini disebabkan bahwa pada panen tersebut pupuk TSP mampu memenuhi ketersedia hara fosfat pada tanah walaupun dalam jumlah sedikit. Unsur $\mathrm{P}$ merupakan komponen penyusun membran sel tanaman, penyusun enzim-enzim, dan unsur $\mathrm{P}$ juga berperan dalam sistesis protein terutama pada jaringan, sintetis karbohidrat serta memacu pembentukan polong (Wijaya, 2014). Menurut Hidayat (2014), bertambahnya suplai fosfor dalam tubuh tanaman akan meningkatkan metabolisme sehingga proses pertumbuhan polong optimal dan jumlah polong meningkat.

\section{Panjang Polong Per Tanaman (cm)}

. Nilai rata-rata panjang polong per tanaman kacang panjang panen I, II, III, IV dan V akibat perlakuan pupuk TSP setelah diuji BNT 0,05 di sajikan pada Tabel 4.

Tabel 4. Nilai Rata-rata Panjang Polong per Tanaman Kacang Panjang Pada Panen I, II, III, IV dan V Akibat Perlakuan Pupuk TSP

\begin{tabular}{cccccc}
\hline \multirow{2}{*}{ Pupuk TSP } & \multicolumn{5}{c}{ Panjang Polong per Tanaman (cm) } \\
\cline { 2 - 6 } & I & II & III & IV & V \\
\hline $\mathrm{T}_{0}$ & $58.70^{\mathrm{a}}$ & $58.10^{\mathrm{a}}$ & $57.16^{\mathrm{a}}$ & $55.83^{\mathrm{a}}$ & $33.22^{\mathrm{a}}$ \\
$\mathrm{T}_{1}$ & $60.66^{\mathrm{b}}$ & $62.28^{\mathrm{b}}$ & $57.89^{\mathrm{a}}$ & $56.72^{\mathrm{a}}$ & $34.23^{\mathrm{a}}$ \\
$\mathrm{T}_{2}$ & $62.79^{\mathrm{c}}$ & $62.81^{\mathrm{b}}$ & $59.68^{\mathrm{b}}$ & $58.08^{\mathrm{b}}$ & $35.17^{\mathrm{b}}$ \\
\hline $\mathrm{BNT}_{0,05}$ & 1.85 & 1.99 & 1.32 & 1.58 & 1.57
\end{tabular}

Keterangan : Angka yang diikuti oleh huruf yang sama pada kolom yang sama berbeda tidak nyata pada Uji BNT 0.05

Tabel 4 memperlihatkan bahwa perlakuan pupuk TSP berpengaruh sangat nyata terhadap panjang polong per tanaman pada panen I, II, III, IV dan V. Panjang polong per tanaman kacang panjang tertinggi pada panen I, II, III, IV dan V dijumpai pada perlakuan TSP dosis 1,20 g/tanaman $\left(\mathrm{T}_{2}\right)$. Adapun panjang polong per tanaman kacang panjang terendah dijumpai pada perlakuan kontrol $\left(\mathrm{T}_{0}\right)$. Hal ini disebabkan oleh pemberian pupuk TSP dengan dosis 1,20 g/tanaman mampu memenuhi kebutuhan hara $\mathrm{P}$ dan mampu menyediakan mikroba pelarut fosfat yang mampu mengikat $\mathrm{N}_{2}$ bebas dari udara serta 
mengubahnya menjadi ammonia serta membantu melarutkan unsur fosfat sehingga ketersedian nitrogen dalam tanah tetap terjaga dan penyerapan fosfat meningkat.

Sesuai dengan pendapat Sutedjo (2010) bahwa fosfor bagi tanaman dapat memperbaiki pertumbuhan generatif terutama pembentukan polong dan biji. Pembentukan dan pemanjangan polong tanaman kacang panjang salah satunya ditentukan oleh kandungan unsur hara P di dalam tanah. Lakitan (2012), bahwa proses pengisian polong sangat dipengaruhi oleh jumlah hara yang tersedia di sekitar tanaman. Proses pengisian polong akan berjalan sempurna jika hara $\mathrm{P}$ berada dalam jumlah yang cukup dan tersedia.

Menurut Sumarno (2011) jumlah dan panjang polong yang terbentuk pada tanaman kacang merupakan komponen yang sangat menentukan produksi karena semakin banyak biji yang terbentuk maka semakin panjang polong dan hasil yang didapatkan juga semakin tinggi. Pembentukan polong tanaman dipengaruhi oleh kondisi dan kandungan media yang digunakan, pupuk $\mathrm{P}$ dibutuhkan tanaman kacang panjang karena unsur $\mathrm{P}$ dapat mengaktifkan pembentukan polong dan pengisian polong yang masih kosong, serta mempercepat pemasakan buah.

\section{Berat Polong Per Tanaman (g)}

Nilai rata-rata berat polong per tanaman kacang panjang panen I, II, III, IV dan V akibat perlakuan pupuk TSP di sajikan pada Tabel 5.

Tabel 5. Nilai Rata-rata Berat Polong per Tanaman Kacang Panjang Pada Panen I, II, III, IV dan V Akibat Perlakuan Pupuk TSP

\begin{tabular}{cccccc}
\hline \multirow{2}{*}{ Pupuk TSP } & \multicolumn{5}{c}{ Berat Polong per Tanaman $(\mathrm{g})$} \\
\cline { 2 - 6 } & $\mathrm{I}$ & $\mathrm{II}$ & $\mathrm{III}$ & $\mathrm{IV}$ & $\mathrm{V}$ \\
\hline $\mathrm{T}_{0}$ & 167.66 & 196.53 & 210.68 & 190.80 & 186.53 \\
$\mathrm{~T}_{1}$ & 180.47 & 206.72 & 214.22 & 198.85 & 193.87 \\
$\mathrm{~T}_{2}$ & 183.70 & 207.76 & 211.64 & 197.49 & 193.22 \\
\hline BNT $_{0,05}$ & - & - & - & - \\
\end{tabular}

Tabel 5 memperlihatkan bahwa perlakuan pupuk TSP berpengaruh tidak nyata terhadap berat polong per tanaman kacang panjang pada panen I, II, III, IV dan V. Hal ini menunjukkan bahwa perlakuan pupuk TSP tidak dapat memicu pertumbuhan berat polong tanaman kacang panjang, karena pada fase pembentukan pembesaran polong, tanaman kacang panjang tidak memberi respon dengan baik sehingga pada taraf pemberian pupuk TSP 
yang rendah maupun lebih tinggi hasil peningkatan berat polong per tanaman yang diperoleh tetap sama. Hal ini disebabkan oleh belum terpenuhinya kebutuhan unsur hara khususnya untuk pembesaran polong atau biji. Kemungkinan dosis ini masih terlalu rendah, sehingga menyebabkan akar tidak mampu mensuplai fosfor ke dalam tubuh tanaman dan metabolisme juga tidak meningkat, sehingga tidak mampu meningkatkan pengisian polong sehingga berat polong juga tidak juga meningkat.

Pembentukan polong tanaman kacang panjang salah satunya ditentukan oleh kandungan unsur hara P di dalam tanah. Lakitan (2012), bahwa proses pengisian polong sangat dipengaruhi oleh jumlah hara yang tersedia di sekitar tanaman. Proses pengisian polong akan berjalan sempurna jika hara $\mathrm{P}$ berada dalam jumlah yang cukup dan tersedia. Dwijoseputra (2014) menyatakan bahwa semua tanaman akan tumbuh baik dan berproduksi tinggi apabila semua unsur hara yang diberikan cukup tersedia dalam jumlah yang sesuai untuk pertumbuhan.

Sudjijo (2013) menyatakan bahwa besarnya jumlah hara yang diserap oleh tanaman sangat bergantung pada pupuk yang diberikan, dimana hara yang diserap oleh tanaman akan dimanfaatkan untuk proses fotosintesis yang pada akhirnya akan berpengaruh terhadap pertumbuhan maupun hasil yang diperoleh.

\section{Berat 100 Biji (g)}

Nilai rata-rata berat 100 biji tanaman kacang panjang panen I, II, III, IV dan V akibat perlakuan pupuk TSP setelah diuji BNT 0,05 di sajikan pada Tabel 6

Tabel 6. Nilai Rata-rata Berat 100 Biji Tanaman Kacang Panjang pada Panen I, II, III, IV dan V Akibat Perlakuan Pupuk TSP

\begin{tabular}{cccccc}
\hline \multirow{2}{*}{ Pupuk TSP } & \multicolumn{5}{c}{ Berat 100 Biji (g) } \\
\cline { 2 - 6 } & I & II & III & IV & V \\
\hline $\mathrm{T}_{0}$ & $3.42^{\mathrm{a}}$ & $3.63^{\mathrm{a}}$ & $3.90^{\mathrm{a}}$ & $3.33^{\mathrm{a}}$ & $3.23^{\mathrm{a}}$ \\
$\mathrm{T}_{1}$ & $3.68^{\mathrm{b}}$ & $4.00^{\mathrm{b}}$ & $4.02^{\mathrm{a}}$ & $3.53^{\mathrm{b}}$ & $3.43^{\mathrm{b}}$ \\
$\mathrm{T}_{2}$ & $3.98^{\mathrm{c}}$ & $4.19^{\mathrm{b}}$ & $4.16^{\mathrm{b}}$ & $3.72^{\mathrm{c}}$ & $3.66^{\mathrm{c}}$ \\
\hline $\mathrm{BNT}_{0,05}$ & 0.22 & 0.31 & 0.18 & 0.14 & 0.16
\end{tabular}

Keterangan : Angka yang diikuti oleh huruf yang sama pada kolom yang sama berbeda tidak nyata pada Uji BNT 0.05

Tabel 6 memperlihatkan bahwa perlakuan pupuk TSP berpengaruh sangat nyata terhadap berat 100 biji tanaman kacang panjang pada panen I, II, III, IV dan V. Berat 100 biji tanaman kacang panjang tertinggi pada panen I, II, III, IV dan V dijumpai pada perlakuan 
TSP dosis 1,20 g/tanaman $\left(\mathrm{T}_{2}\right)$. Adapun berat 100 biji tanaman kacang panjang terendah dijumpai pada perlakuan kontrol $\left(\mathrm{T}_{0}\right)$. Hal ini disebabkan oleh pemberian pupuk TSP dengan dosis 1,20 g/tanaman dapat memenuhi ketersedia hara fosfat dalam keadaan tercukupi untuk memicu pertumbuhan biji pada tanaman kacang panjang, selain itu juga disebabkan oleh kondisi lingkungan yang mendukung yaitu meliputi keadaan tanah dan lahan yang digunakan tidak ternaungi sehingga sinar matahari yang dibutuhkan tercukupi. Selama masa stadia pematangan polong, tanaman kacang memelukan memerlukan kondisi lingkungan yang kering agar diperoleh kualitas biji yang baik. Kondisi lingkungan yang kering akan mendorong proses pemasakan biji lebih cepat dan bentuk biji seragam. Menurut Irwan (2016) bahwa ukuran dan bentuk polong menjadi maksimal pada saat awal periode pemasakan biji.

Hidayat (2014), menyatakan bahwa bertambahnya suplai fosfor dalam tubuh tanaman akan meningkatkan metabolism, sehingga proses pengisian biji optimal dan berat biji meningkat. Pemberian pupuk TSP 1,20 g/tanaman dapat meningkatkan produksi dibandingkan tanpa pemberian pupuk TSP. Menurut Indriati (2014), fosfat berperan dalam pembentukan biji, mempercepat pembentukan bunga serta masaknya buah dan biji, meningkatkan rendemen dan komponen hasil panen tanaman biji-bijian.

Sutedjo (2010) mengatakan bahwa unsur Fosfat berperan dalam meningkatkan pengisian biji tanaman sehingga dengan pemberian Fosfat yang tinggi akan meningkatkan berat biji tanaman. Semakin banyak unsur Fosfat tersedia bagi tanaman, maka semakin banyak pula yang dapat diserap tanaman, sehingga fotosintesis akan meningkat dan pada akhirnya akan meningkatkan berat biji per tanaman.

\section{Produktivitas (Ton/Ha)}

Nilai rata-rata produktivitas tanaman kacang panjang panen I, II, III, IV dan V akibat perlakuan pupuk TSP di sajikan pada Tabel 7. 
Tabel 7. Nilai Rata-rata Produktivitas Tanaman Kacang Panjang pada Panen I, II, III, IV dan V Akibat Perlakuan Pupuk TSP

\begin{tabular}{cccccc}
\hline \multirow{2}{*}{ Pupuk TSP } & \multicolumn{5}{c}{ Produktivitas (Ton/Ha) } \\
\cline { 2 - 6 } & I & II & III & IV & V \\
\hline $\mathrm{T}_{0}$ & 4.55 & 5.41 & 5.80 & 4.88 & 4.85 \\
$\mathrm{~T}_{1}$ & 4.93 & 5.76 & 5.88 & 5.14 & 4.69 \\
$\mathrm{~T}_{2}$ & 4.96 & 5.79 & 6.14 & 5.33 & 5.15 \\
\hline
\end{tabular}

$\mathrm{BNT}_{0,05}$

Tabel 7 memperlihatkan bahwa perlakuan pupuk TSP berpengaruh tidak nyata terhadap produktivitas tanaman kacang panjang pada panen I, II, III, IV dan V. Hal ini menunjukkan perlakuan pupuk TSP tidak dapat memicu produktivitas tanaman kacang panjang, walaupun perlakuan pupuk TSP berpengaruh tidak nyata terhadap hasil yang didapatkan, akan tetapi produktivitas yang didapat dari setiap panen sama dan bahkan lebih tinggi dari deskripsi varietas. Hal ini disebakan oleh faktor lingkungan dan tanah yang subur dan gembur sesuai dengan syarat tumbuh yang diperlukan oleh tanaman kacang panjang.

Setiap tanaman menghendaki keadaan lingkungan yang sesuai untuk pertumbuhannya. Pada kondisi lingkungan yang sesuai, tanaman kacang panjang dapat tumbuh dengan baik dan berproduksi tinggi. Apabila faktor lingkungan mendukung seperti ketersediaan air, $\mathrm{CO}_{2}$, suhu, unsur hara dan cahaya yang mencukupi maka pertumbuhan berat polong kacang panjang akan semakin meningkat. Hal ini sesuai dengan pendapat Darjanto dan Satifah (2012) bahwa faktor yang mempengaruhi saat pembentukan polong adalah faktor genetik yaitu sifat yang turun temurun, sebagian lagi faktor lingkungan seperti suhu, cahaya dan air.

Prawitasari (2013), menjelaskan bahwa perubahan pertumbuhan kearah perkembangan produksi tanaman dipengaruhi oleh kemampuan kerja enzim dalam tubuh tanaman dan faktor lingkungan. Pertumbuhan dan perkembangan organ ditentukan oleh suatu proses yang dinamakan fotosintesis bila hasilnya baik maka akan menghasilkan pertumbuhan dan perkembangan tanaman yang baik pula, hal ini dapat terukur pada penambahan jumlah organ tanaman, perluasan sel-sel dan proses fotosintsis dapat berjalan dengan baik bila faktor (hara, suhu dan udara) yang mempengaruhi proses tersebut berada pada kondisi optimum.

Menurut Gardner dkk. (1991) dalam Sarief (2016), menyatakan ada dua faktor yang mempengaruhi kecepatan hasil tanaman pada tanaman yaitu faktor eksternal (lingkungan) 
seperti cahaya matahari dan ketersediaan unsur hara didalam tanah dan faktor internal (genetik) yaitu apabila umur tanaman sudah melewati masa vegetatif maka tanaman akan tumbuh dan berproduksi dengan baik.

\section{KESIMPULAN DAN SARAN}

\section{Kesimpulan}

Permberian pupuk TSP berpengaruh sangat nyata terhadap pertumbuhan tinggi tanaman umur 20, 40 dan 60 HST, jumlah polong, jumlah polong per tandan, panjang polong dan berat 100 biji tanaman kacang panjang. Perlakuan terbaik dijumpai pada perlakuan pupuk TSP dosis $1,20 \mathrm{~g} / \operatorname{tanaman}\left(\mathrm{T}_{2}\right)$.

\section{Saran}

Berdasarkan hasil penelitian yang telah dilaksanakan disarankan untuk menggunakan pupuk TSP dengan dosis 1,20 g/tanaman, agar mendapatkan pertumbuhan dan hasil tanaman yang optimal pada tanaman kacang panjang. 


\section{DAFTAR PUSTAKA}

Badan Pusat Statistik Bireuen. 2017. Bireuen Regency In Figures. Dinas Pertanian Kabupaten Bireuen. Bireuen

Barus, W. A, Hadriman K,, Muhammad. A.S. 2014. Respon Pertumbuhan dan Produksi Kacang Hijau (Phaseolus radiatus 1.) Akibat Penggunaan Pupuk Organik Cair dan Pupuk TSP. Jurnal Agrium Program Studi Agroekoteknologi Fakultas Pertanian UMSU Medan.

Darjanto S. Satifah. 2013. Pengetahuan Dasar Biologi Bunga dan Teknik Penyerbukan Silang Buatan. PT Gramedia, Jakarta.

Dwijoseputro, D. 2014. Dasar-Dasar Mikrobiologi. Jakarta: Djambatan.

Gardner, 1991. Fisiologi Tanaman Budidaya. UI Press: Jakarta.

Hardjoloekito, A.J.H. 2012. Pengaruh pengapuran dan pemupukan $\mathrm{P}$ terhadap pertumbuhan dan hasil tanaman kedelai (Glycine max L.) pada tanah latosol. Jurnal Media Soerjo, volume 5 (2) : 1-19.

Haryanto, E., 2013. Budidaya Kacang Panjang, Penebar Swadaya. Jakarta.

Hidayat, 2014. Peranan Zeolit Nanopori Termodifikasi sebagai Material Pengontrol Pelepasan Pupuk Urea, (Online), (http://artikel.dikti.go.id/ index.php/PKMP/article/download/451/451.diakses 5 maret 2021

Indriati, T.R. 2014. Pengaruh Dosis Pupuk Organik dan Populasi Tanaman terhadap Pertumbuhan serta Hasil Tumpangsari Kedelai (Glycine max L.) dan Jagung (Zea mays L.). Tesis. Program Pascasarjana Universitas Sebelas Maret. Surakarta.

Irwan, W.A. 2016. Budidaya Tanaman Kedelai (Glycine max (L.) Merill). Universitas Padjajaran Press. Jatinangor.

Jumrawati. 2017. Efektifitas Inokulasi Rhizobium sp terhadap Pertumbuhan dan Hasil Tanaman Kedelai Pada Tanah Jenuh Air. Jurnal Dinas Pertanian Provinsi Sulawesi Tengah. 47-55.

Lakitan, B 2012. Dasar-dasar Fisiologi Tumbuhan. Raja Grafindo Persada. Jakarta.

Novriani. 2010. Alternatif Pengelolaan Unsur Hara P (Fosfor) Pada Budidaya Jagung. Jurnal Agronobi S, Vol. 2(3)- $42-49$

Novizan. 2012. Petunjuk Pemupukan yang Efektif. Agromedia Pustaka. Jakarta.

Prawitasari, T. 2013. Siknal Fisiologi Pada Transisi ke Pertumbuhan Perkembangan Reproduktif. P2KSDM, Bogor. 
Rosmawaty.T., Selvia S., Murdiono. 2018. Aplikasi MOL Keong Mas dan TSP dalam Meningkatkan Produksi Tanaman Kacang Tanah (Arachis hypogaea L). Seminar Nasional Dalam Rangka Dies Natalis UNS Ke 42 Tahun 2018. Fakultas Pertanian Universitas Islam Riau.

Sarief, E. S. 2016. Kesuburan Tanah dan Pemupukan Tanah Pertanian. Pustaka Buana. Bandung.

Sudjijo. 2013. Pengaruh Beberapa Jenis Pupuk Organik terhadap Pertumbuhan dan Hasil Wortel. Jurnal Holtikultura vol 4( 2) 32-38

Sumarno. 2011. Teknik Budidaya Kacang Tanah. Sinar Baru. Bandung.

Sutedjo, M. M. 2010. Pupuk dan Cara Pemupukan. Jakarta. Rieneka Cipta

Syafria, A. Zahrah, S., Rosmawaty T. 2013. Aplikasi pupuk P (TSP) dan Urin Sapi Pada Tanaman Kacang Hijau (Vigna radiata. L). Skripsi. Fakultas Pertanian Universitas Islam. Riau.

Tapehe, Yusuf. 2015.Statistika dan Rancangan Percobaan. Jakarta: EGC

Wijaya. 2014. Nutrisi Tanaman Sebagai Penentu Kualitas Hasil dan Resistensi Alami Tanaman. Jurnal Agrosains. 9 (2): 12-15.

Zahrah, S. 2011. Respons berbagai varietas kedelai terhadap pemberian pupuk NPK organik. Jurnal Teknobiologi. 3(3) 11-15 